\title{
Modelling of the Influence of Tensile Test Speed on the Fracture Load
}

\author{
K.M. Khaled ${ }^{1 *}$ and G.M. Mahmoud ${ }^{1}$ \\ ${ }^{1}$ National Institute of Standards, El Sadat St, El-Haram, Code 12211, Giza, Egypt
}

\begin{abstract}
This investigation focuses on modelling the fracture zone of four materials at different test speeds. The influence of these test speeds on the fracture zone formula was investigated as well. The fracture behaviour of materials is an important parameter which greatly affects the performance of these materials. In this paper, an empirical formula was generated to predict the fracture zone. This formula was produced from experimental characterisation of the fracture process at different loading rates for some engineering materials. Statistical analysis was done for the results being obtained from the experimental work to verify the accuracy of this formula, and it was found that it can introduce an accurate base for fracture zone prediction and determination. It was noted that at fracture process initiation, there are no significant effects of varying loading rate; this effect is increased with increasing the fracture process propagation.
\end{abstract}

Keywords: tensile testing; fracture mechanics; loading rate; fracture zone; dynamic loading

\section{INTRODUCTION}

Engineering materials are classified in accordance to their deformation at fracture (i.e., brittle or ductile), to the form and appearance of fracture where ductile fracture produces less serious problems than brittle fracture under the same operating conditions, and to the crystallographic manner in which the fracture occurs (i.e., sliding, cleavage) (Hutiu et al., 2018). Among the various failure mechanisms introduced (Fan et al., 2017), investigating those associated with a brittle and ductile fracture in metallic alloys is important. Ductile fracture includes failure plastic instability or by cavitation.

Brittle fracture includes both intergranular fracture and cleavage. Recently developed advanced high-strength materials like advanced ceramics and nanocrystalline metallic materials, usual failure in a catastrophic brittle behaviour, which makes it urgent to determine a reasonable fracture criterion to predict their brittle fracture behaviours (Pineau et al., 2016; Guptaab et al., 2015). Though there are different models and rules for engineering metallic material fracture, it makes many troubles for engineering application, because of lack of the reasonable description of fracture principle and change law (Qu and Zhang, 2013). The fracture resistance of many materials such as composite materials as well as some other metallic materials is increased by stiffening technique because shielding of the cracks ends by a nonlinear area of microcracking distribution or voids formalisation. In those materials, more careful definitions are required for the fracture energy, and the fracture behaviours of the sole material characteristic have not been represented (Carpinteri et al., 2003).

The size of the nonlinear fracture process area at the cracks tips is another essential characteristic that needs to be investigated (Andrew Braham, 2016). It is required to determine the size of the fracture zone of microcracking or voids formation. It could be determined by the size of the inhomogeneities in material microstructure, and if the size of this fracture process zone is trivial in comparing with the structure dimensions or specimens, the fracture behaviour approaches that of linear elastic fracture mechanics. If the

*Corresponding author's e-mail: khaled_fmmd_nis@yahoo.com 
size of this zone includes all or most of the structure or specimen surface, the failure is determined by yield criterion or determination of the strength. If the size of this zone is moderate, the fracture behaviours are transitive between the linear elastic fracture mechanics and the strength criterion. This transitive behaviour which is important for many applications, and it was focused on it in this investigation.

The nonlinear fracture process area (fracture zone) gives relevant altitude to the size effect which might be explained by a rather simple size effect law recently proposed by Bazant (Qu and Zhang, 2013; Guo and Hu, 2013). It has been shown that this law can be utilised to determine the fracture energy of the material simply by the measurement of the maximum loads of geometrically similar specimens of sufficiently different sizes (Al-Maliky and Parry, 2004; Bazant and Kazem, 1990). In tensile testing the determination of the fracture zone is greatly affected by the testing machine force transducer's response time is an important parameter to be considered for practical applications. The typical force sensor behaviour is the same as an oscillated stiff spring, to achieve an accurate determination for the specified testing load value, the load transducer must achieve that is, stop oscillating - in less time than the required loading period (Bazant, 1985). For high-speed check loading (high loading rate of tensile testing) or rotary filling machine requires fast response force sensors. Such fast response force sensors inhibit their natural oscillating frequency when a force is applied to them. However, although, the force sensors do not remove vibrations applied to them from the outer sources, such as nearby equipment, so it is still needed to isolate the force sensors from damage the force sensors once when the season changes to correct for any temperature-caused such vibration sources (Bazant et al., 1987).

At a high loading rate, it is required to ensure that only the testing load is transmitted to each force sensor. Other loads values, such as environmental like, vibration, shock loading, large temperature changes, sudden loading and pressure differentials occurs when heavy material is dumped on the force sensor which is occurred at high loading rate, tending to greater forces than the system's rated capacity, and hence can generate errors in the force sensor signal which tends to inaccurate determination of the fracture point (Alves, 2000).
The principal objective of this paper is to determine the fracture zone and to generate an empirical mathematical model to detect this fracture process zone and to make a relation between the test speed and this zone.

\section{METHODOLOGY}

\section{A. Testing Material Characterisation}

Different testing materials were used for this investigation the mechanical properties of these materials can be summarised as follow:

Poly (methyl methacrylate) (PMMA): with the tensile strength of $48-76 \mathrm{MPa}$, shear modulus, 1700MPa (dynamic, $\left.25^{\circ} \mathrm{C}\right)$;

Copper: Copper alloy with a grade of C106/CW024A. The yield point is reported as either a $0.5 \%$ extension under load or as a $0.2 \%$ offset;

Steel rode: St37 rods were used in this investigation in the form of dumb shape with the Yield strength of $235 \mathrm{Mpa}$ and Tensile Strength of $360 \mathrm{Mpa}$;

Aluminium: Aluminum 6061-T6 samples were used in this investigation with the Yield Strength of $276 \mathrm{Mpa}$, 68.9Gpa Modulus of Elasticity, and 17 \% Elongation.

\section{B. Testing Apparatus and Setup}

Data on the effect of strain rate on fracture point and tensile properties of materials is scarce due to data sampling rate difficulties (ISO 7500-1, 2018). For accurate determination of the fracture zone, there are two major critical issues to determine the fracture points at high loading rates tensile testing:

- Intense oscillation of the applied force deteriorates the quality of the stress-strain curve;

- Continues monitoring of the existing strain and force (dynamic force measuring amplifier) is not reliable and not accurate at high strain rates.

Due to these difficulties, the following apparatuses were used in this investigation;

- The fully computerised tensile testing machine is used to perform the required tests; this machine was 
classified as 0.5 accuracy class in accordance with (ISO 7500-1, 2018). This machine was provided by a high precision extensometer to measure the displacement (Figure 1).

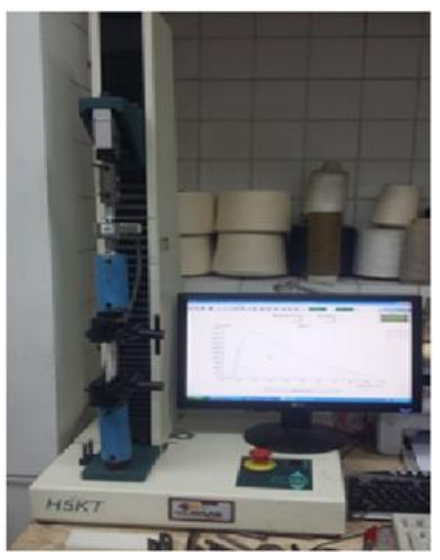

Figure 1. 5kN Tensile testing machine

- A high-speed transient recorder and data acquisition system is the modular platform for fast measurements of mechanical parameters. A transient recorder, data recorder, and data acquisition system provide all the features expected from a transient recorder. Genesis High Speed is provided with data acquisition cards with sampling rates of $20 \mathrm{KS} / \mathrm{s}$ to $100 \mathrm{MS} / \mathrm{s}$. This modular platform (interfaced with $5 \mathrm{kN}$ dynamic force transducer) was used to monitor the testing force utilising the fast sampling rate to monitor the behaviour of the tested material from the force point of view (Figure 2).

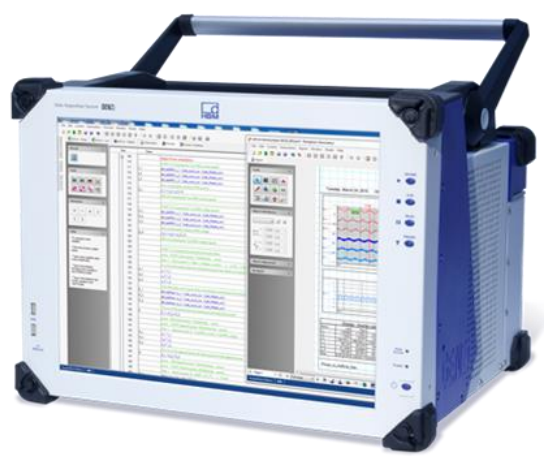

Figure 2. High-Speed Recorder

- Dynamic Load Cell: for measurement of tensile dynamic force, this force transducer is suitable for very fast measurements. The capacity of this force transducer is $5 \mathrm{kN}$ with an accuracy class of 0.5 (Figure 3).

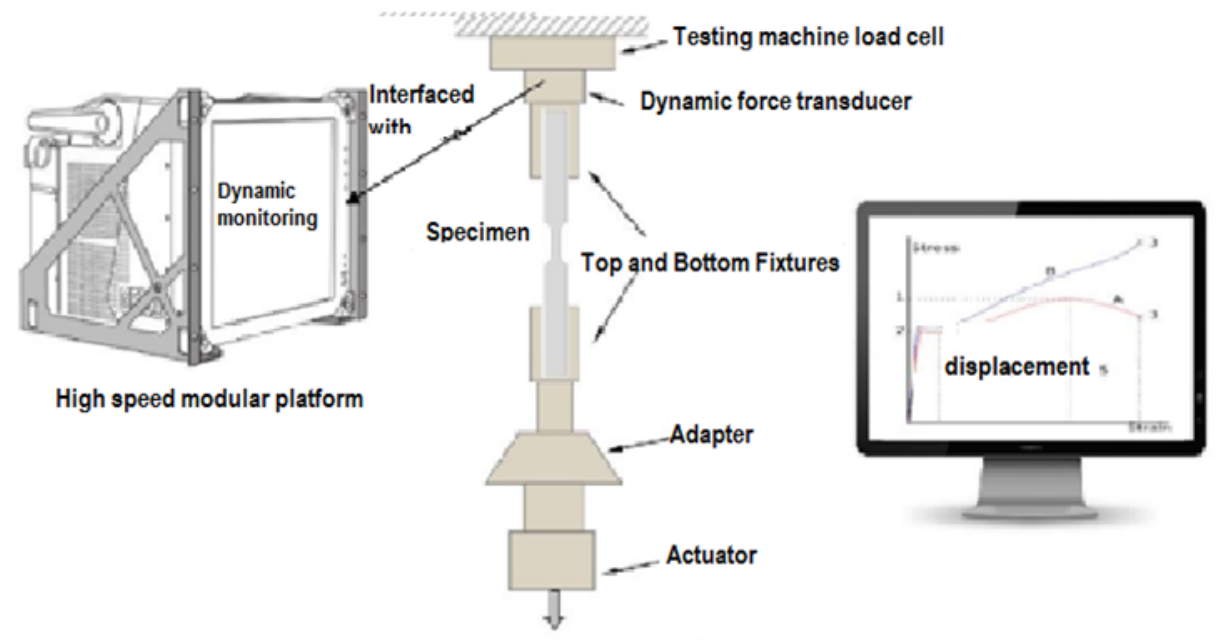

Figure 3. Setup of the measuring system

\section{Test Procedure}

Three machine speeds $(5,10$ and 20$) \mathrm{mm} / \mathrm{min}$ were used to test 3 samples per each rate for the selected materials. The 
samples were prepared to fit the machine grips in tension mode. The top of the upper grip was assembled to the dynamic force transducer used. Warming up time for the equipment and the stability of the environmental conditions before and during the tests were observed. The dynamic force transducer interfaced with the modular platform for force/time fast measurement. Results were analysed, and force rate versus failure time curves was monitored. The fracture point is similar to applying inverse step force function on both the testing machine (force transducer and measuring amplifier) and the material under test.

Therefore, in this investigation, the fracture point was enlarged to present the fracture zone. In order to specify this fracture zone, the fracture yield point of each test curve (force-time) was picked, then move downwards for a constant time (specifically $571 \mathrm{~ms}$ ). To have a clear trend line for the results before the fracture point, all test measurements, for all tested materials, were checked and found that the 571ms is adequate for all materials to be the start point of this fracture zone. The zero-force is considered the end of the fracture zone. To unify the representation of the fracture zone results for all the tested materials, the force value at the start point of the fracture zone is considered zero force and the subsequent forces were subtracted from its actual value.

\section{RESULTS AND DISCUSSION}

Figure 4 shows the fracture zone of the steel materials for the three different machine speeds as a sample from the four tested materials. It was shown that before and after the fracture yield point, there are two approximately straight lines; the line before has a specific decay and the line after has great decay to reach the zero force. The results of the fracture zone give the fracture curve as a force-time relation.

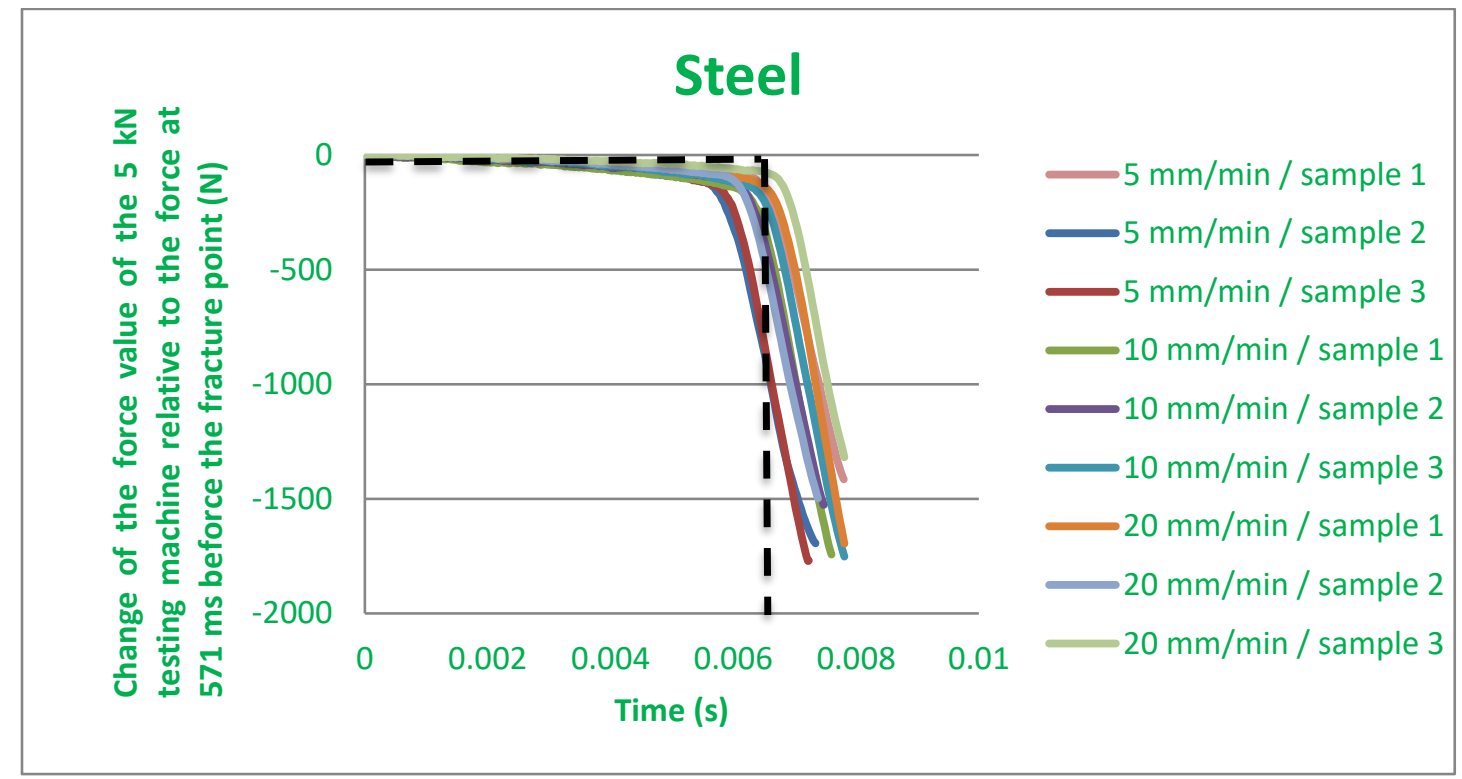

Figure 4. Fracture zone of steel (st37)

From Figure 4 and 5, it was noted that at fracture curve initiation there are no significant effects of varying loading rate, this effect is increased with increasing the fracture process propagation, at high loading rate the fracture zones can be extended more than estimated from low loading rate.

To generate the empirical formula to predict the fracture zone, statistical analysis was done for the results being obtained from the experimental work, and regression coefficients were calculated to estimate the relationship between a set of independent variables and some dependent variables. Different exponential functions are used to fit the results obtained from the experiments; the best fit exponential function is giving below.

$$
y=A \times \exp \left(R_{0} \times x\right)
$$

Where: 
$\mathrm{x}: \quad$ time $(\mathrm{s})$

$\mathrm{y}: \quad$ force value $(\mathrm{N})$

A: $\quad$ initial force value $(\mathrm{N})$

Ro: force loading rate $(\mathrm{N} / \mathrm{s})$
The adjusted R-square is the best estimate of the degree of relationship in the basic population. Table 1 shows the values of the coefficients from Equation 1 and the corresponding Rsquares. The results of R- squares shown to give a quite fair degree of relationship.

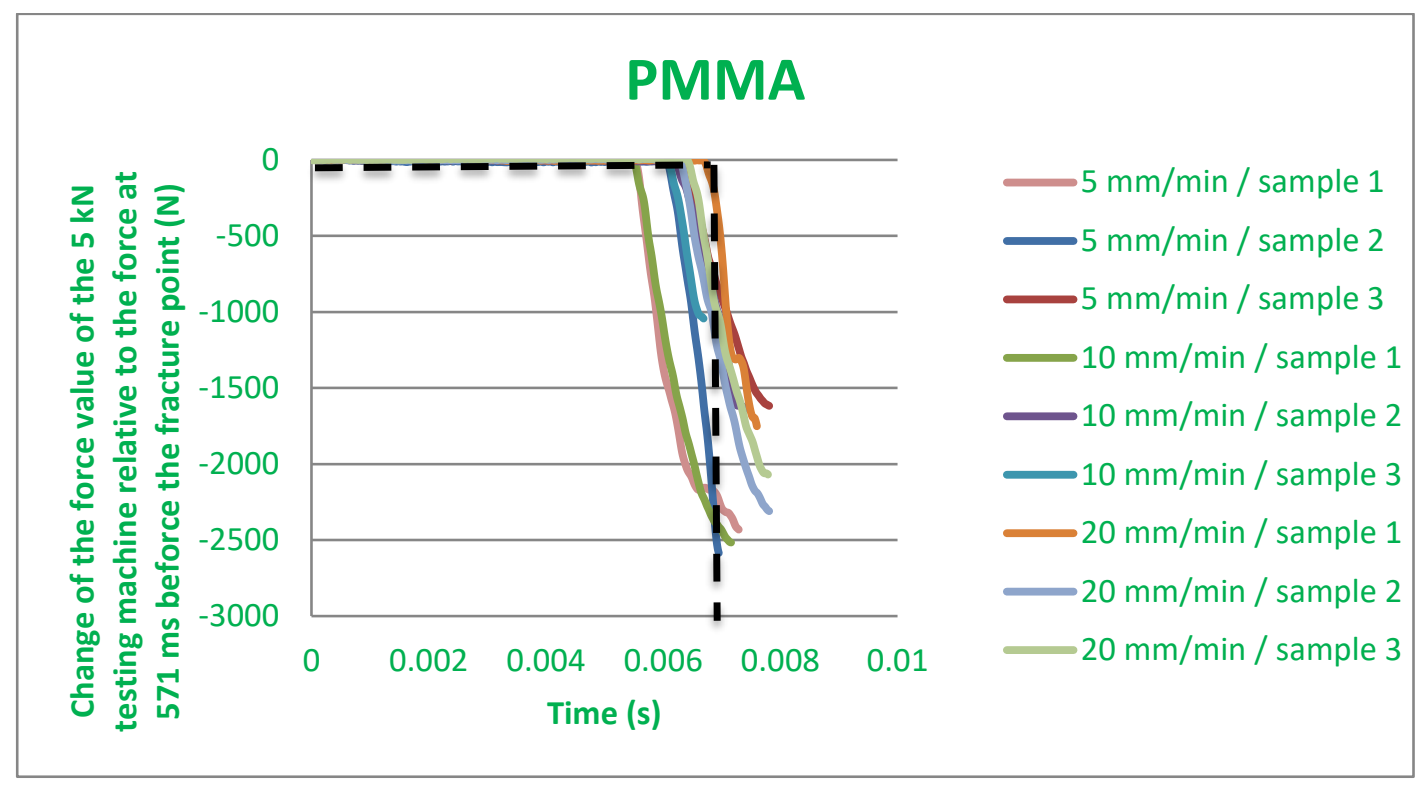

Figure 5. Fracture zone of PMMA

Table 1. Coefficients of the fracture zone fracture zone

\begin{tabular}{|c|c|c|c|c|c|}
\hline \multirow{2}{*}{ Material } & \multirow{2}{*}{$\begin{array}{l}\text { Machine } \\
\text { loading rate } \\
\text { (mm/min) }\end{array}$} & \multirow{2}{*}{ Sample } & \multicolumn{2}{|c|}{$y=A \times \exp \left(R_{0} \times x\right)$} & \multirow{2}{*}{$\begin{array}{l}\text { Adj. R-squares } \\
\mathrm{R}^{2}\end{array}$} \\
\hline & & & $A$ & $R_{\mathrm{O}}$ & \\
\hline \multirow{9}{*}{ Steel } & \multirow{3}{*}{5} & 1 & -0.02093 & 1442.341 & 0.97944 \\
\hline & & 2 & -0.34616 & 1181.635 & 0.97407 \\
\hline & & 3 & -0.07916 & 1403.714 & 0.98197 \\
\hline & \multirow{3}{*}{10} & 1 & -0.04773 & 1398.534 & 0.97917 \\
\hline & & 2 & -0.03295 & 1453.886 & 0.98142 \\
\hline & & 3 & -0.04182 & 1379.933 & 0.98146 \\
\hline & \multirow{3}{*}{20} & 1 & -0.01860 & 1462.218 & 0.98209 \\
\hline & & 2 & -0.02658 & 1501.308 & 0.97970 \\
\hline & & 3 & -0.01384 & 1459.114 & 0.94045 \\
\hline \multirow{8}{*}{ PMMA } & \multirow{3}{*}{5} & 1 & -0.00310 & 2110.625 & 0.94045 \\
\hline & & 2 & -0.00002 & 2742.651 & 0.98023 \\
\hline & & 3 & -0.01030 & 1590.721 & 0.95096 \\
\hline & \multirow{3}{*}{10} & 1 & -0.45706 & 1255.539 & 0.93202 \\
\hline & & 2 & -0.00012 & 2286.211 & 0.97808 \\
\hline & & 3 & 0.00000 & 4522.782 & 0.96944 \\
\hline & \multirow{2}{*}{20} & 1 & 0.00000 & 4701.334 & 0.96078 \\
\hline & & 2 & -0.17080 & 1243.449 & 0.93494 \\
\hline
\end{tabular}




\begin{tabular}{|c|c|c|c|c|c|}
\hline & & 3 & -0.03285 & 1449.617 & 0.93746 \\
\hline \multirow{9}{*}{ Aluminum } & \multirow{3}{*}{5} & 1 & -0.33317 & 880.4972 & 0.99326 \\
\hline & & 2 & -0.02598 & 913.2547 & 0.99298 \\
\hline & & 3 & -0.44783 & 941.8274 & 0.99528 \\
\hline & \multirow{3}{*}{10} & 1 & -0.11355 & 1201.796 & 0.98374 \\
\hline & & 2 & -0.93258 & 1109.256 & 0.98793 \\
\hline & & 3 & -0.12144 & 1225.69 & 0.99463 \\
\hline & \multirow{3}{*}{20} & 1 & -1.02435 & 661.917 & 0.99800 \\
\hline & & 2 & -0.08579 & 1230.387 & 0.98871 \\
\hline & & 3 & -0.17526 & 869.6915 & 0.99054 \\
\hline \multirow{9}{*}{ Copper } & \multirow{3}{*}{5} & 1 & -2.16403 & 968.7012 & 0.99069 \\
\hline & & 2 & -10.3246 & 688.1021 & 0.99253 \\
\hline & & 3 & -3.7452 & 547.9225 & 0.99479 \\
\hline & \multirow{3}{*}{10} & 1 & -1.59422 & 1010.312 & 0.99158 \\
\hline & & 2 & -1.68862 & 658.3257 & 0.99137 \\
\hline & & 3 & -0.04220 & 1399.423 & 0.98169 \\
\hline & \multirow{3}{*}{20} & 1 & -1.72506 & 1015.967 & 0.99192 \\
\hline & & 2 & -1.36584 & 871.211 & 0.99371 \\
\hline & & 3 & -2.5125 & 599.964 & 0.99606 \\
\hline
\end{tabular}

To estimate the contribution of data sets of experimental measurements, the significance of each measurement on the mean value of each measurement group, for the two coefficients $A$ and $R_{0}$, is calculated as follows:

$$
\text { Significance of } A \text { or } R_{\mathrm{o}}\left(S_{\mathrm{i}}\right)=\text { mean - value }
$$

This significance $\left(S_{\mathrm{i}}\right)$ will be used to calculate the weighted mean of the coefficients $A$ (symbol $a$ ) and $R_{\mathrm{o}}(\operatorname{symbol} b)$ as follows:

$$
\begin{aligned}
& a=\sum \frac{A_{i}}{S_{i}^{2}} \\
& b=\sum \frac{R_{0_{i}}}{S_{i}^{2}}
\end{aligned}
$$

The weighted uncertainties of these two weighted means are calculated as follows, in order to improve the confidence in the formula obtained (confidence level at 95\% and coverage factor of $\mathrm{k}=2$ ):

$$
u_{a \mathrm{orb}}=\sqrt{\frac{1}{\sum \frac{1}{S_{i}^{2}}}}
$$

Table 2 shows the weighted means, and the corresponding uncertainties of the coefficients $A$ and $R_{0}$ resulted from Equations 2 to 5. Table 2 shows that the weighted mean at different speeds, of the four selected materials, are different for both coefficients ( $A$ and $R_{0}$ ) which reflects the effect of the machine speed on the fracture zone. The calculated weighted uncertainties of the coefficients $A$ and $R_{0}$ considered fair as a result of the tensile test.

Figures 6 to 9 show the graphical representation of the results of the coefficient $A$. For the ductile materials, steel, aluminium and copper, the values of $A$ at machine speed $5 \mathrm{~mm} / \mathrm{min}$ has a certain value then decreased, regardless of the sign, to reach a stable level from speed $10 \mathrm{~mm} / \mathrm{min}$ to $20 \mathrm{~mm} / \mathrm{min}$, on the other hand, for the brittle material, PMMA, it has opposite behaviour. At machine speed $5 \mathrm{~mm} / \mathrm{min}$ has a certain value then increased, regardless of the sign, to reach a stable level from speed $10 \mathrm{~mm} / \mathrm{min}$ to $20 \mathrm{~mm} / \mathrm{min}$. 
Table 2. The weighted means and the corresponding uncertainties of the coefficients $A$ and $R_{0}$

\begin{tabular}{|c|c|c|c|c|c|c|c|c|c|}
\hline \multirow{2}{*}{ Material } & $\begin{array}{l}\text { Machin } \\
\text { e speed }\end{array}$ & Mean & $\begin{array}{c}\text { Significanc } \\
\text { e }\left(S_{i}\right)\end{array}$ & $\begin{array}{l}\text { Weighted } \\
\text { mean }(a)\end{array}$ & $\begin{array}{c}\text { Weighted } \\
\text { uncertainty } \\
\left(u_{a}\right)\end{array}$ & Mean & $\begin{array}{c}\text { Significanc } \\
\text { e }\left(S_{i}\right)\end{array}$ & $\begin{array}{l}\text { Weighted } \\
\text { mean }(b)\end{array}$ & $\begin{array}{c}\text { Weighted } \\
\text { uncertaint } \\
\text { y }\left(u_{b}\right)\end{array}$ \\
\hline & $\mathrm{mm} / \mathrm{mi}$ & \multicolumn{4}{|c|}{$A$} & \multicolumn{4}{|c|}{$R_{\mathrm{o}}$} \\
\hline \multirow{9}{*}{ Steel } & \multirow{3}{*}{5} & \multirow{3}{*}{$\begin{array}{l}- \\
0.1488\end{array}$} & 0.1278 & \multirow{3}{*}{-0.0904} & \multirow{3}{*}{0.0584} & \multirow{3}{*}{$\begin{array}{l}1342.563 \\
1\end{array}$} & 99.7775 & \multirow{3}{*}{$\begin{array}{l}1392.162 \\
8\end{array}$} & \multirow{3}{*}{49.5997} \\
\hline & & & 0.1974 & & & & 160.9281 & & \\
\hline & & & 0.0696 & & & & 61.1506 & & \\
\hline & \multirow{3}{*}{10} & \multirow{3}{*}{$\begin{array}{l}- \\
0.040 \\
8\end{array}$} & 0.0069 & \multirow{3}{*}{-0.0418} & \multirow{3}{*}{0.0010} & \multirow{3}{*}{$\begin{array}{l}1410.784 \\
3\end{array}$} & 12.2503 & \multirow{3}{*}{$\begin{array}{l}1399 \cdot 776 \\
4\end{array}$} & \multirow{3}{*}{11.0080} \\
\hline & & & 0.0079 & & & & 43.1012 & & \\
\hline & & & 0.0010 & & & & 30.8509 & & \\
\hline & \multirow{3}{*}{20} & \multirow{3}{*}{$\begin{array}{l}- \\
0.0197\end{array}$} & 0.0011 & \multirow{3}{*}{-0.0186} & \multirow{3}{*}{0.0010} & \multirow{3}{*}{$\begin{array}{l}1474.213 \\
3\end{array}$} & 11.9953 & \multirow{3}{*}{$\begin{array}{l}1465 \cdot 339 \\
2\end{array}$} & \multirow{3}{*}{8.8741} \\
\hline & & & 0.0069 & & & & 27.0943 & & \\
\hline & & & 0.0058 & & & & 15.0990 & & \\
\hline \multirow{9}{*}{ PMMA } & \multirow{3}{*}{5} & \multirow{3}{*}{$\begin{array}{l}- \\
0.0045\end{array}$} & 0.0014 & & & & $37 \cdot 3737$ & & \\
\hline & & & 0.0045 & -0.0032 & 0.0013 & $214 / .999$ & 594.6521 & $2110 . / 02$ & 37.2169 \\
\hline & & & 0.0058 & & & & 557.2784 & & \\
\hline & & & 0.3047 & & & & 1432.6383 & & \\
\hline & 10 & 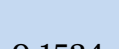 & 0.1523 & -0.0508 & 0.1016 & $2000.1 / 7$ & 401.9662 & 2309.49 & 378.6864 \\
\hline & & & 0.1524 & & & & 1834.6045 & & \\
\hline & & & 0.0679 & & & & 2236.5340 & & \\
\hline & 20 & 50 & 0.1029 & -0.0381 & 0.0298 & & 1221.3512 & 1727.7115 & 737.0885 \\
\hline & & & 0.0350 & & & & 1015.1827 & & \\
\hline & & & 0.0642 & & & & 31.3626 & & \\
\hline & 5 & 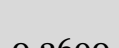 & 0.2430 & -0.3276 & 0.0586 & 911.8598 & 1.3949 & 913.2518 & 1.3921 \\
\hline & & & 0.1788 & & & & 29.9676 & & \\
\hline & & & 0.2756 & & & & 22.8821 & & \\
\hline um & 10 & 0.3892 & 0.5434 & -0.2081 & 0.1811 & 8 & 69.6583 & 1190.020 & 19.7142 \\
\hline & & & 0.2678 & & & & 46.7761 & & \\
\hline & & & 0.5959 & & & & 258.7482 & & \\
\hline & 20 & & 0.3427 & -0.2358 & 0.1927 & 920.6652 & 309.7218 & 871.2923 & 49.3729 \\
\hline & & & 0.2532 & & & & 50.9737 & & \\
\hline & & & 1.2473 & & 0.3042 & & 233.7926 & & \\
\hline Copper & 5 & -3.7154 & 0.9133 & -3.7154 & & 734.9086 & 46.8065 & 690.3359 & 44.5727 \\
\hline & & & 0.3339 & & & & 186.9861 & & \\
\hline
\end{tabular}




\begin{tabular}{|c|c|c|c|c|c|c|c|c|}
\hline \multirow{3}{*}{10} & \multirow{3}{*}{-1.1083} & 0.4859 & \multirow{3}{*}{-1.4600} & \multirow{3}{*}{0.3517} & \multirow{3}{*}{$\begin{array}{l}1022.686 \\
9\end{array}$} & 12.3752 & \multirow{3}{*}{$\begin{array}{l}1010.325 \\
5\end{array}$} & \multirow{3}{*}{12.3614} \\
\hline & & 0.5803 & & & & 364.3612 & & \\
\hline & & 1.0661 & & & & 376.7364 & & \\
\hline \multirow{3}{*}{20} & \multirow{3}{*}{$\begin{array}{l}- \\
1.8678\end{array}$} & 0.1427 & \multirow{3}{*}{-1.7335} & \multirow{3}{*}{0.1343} & \multirow{3}{*}{829.0472} & 186.9195 & \multirow{3}{*}{869.5302} & \multirow{3}{*}{40.4830} \\
\hline & & 0.5020 & & & & 42.1638 & & \\
\hline & & 0.6447 & & & & 229.0832 & & \\
\hline
\end{tabular}

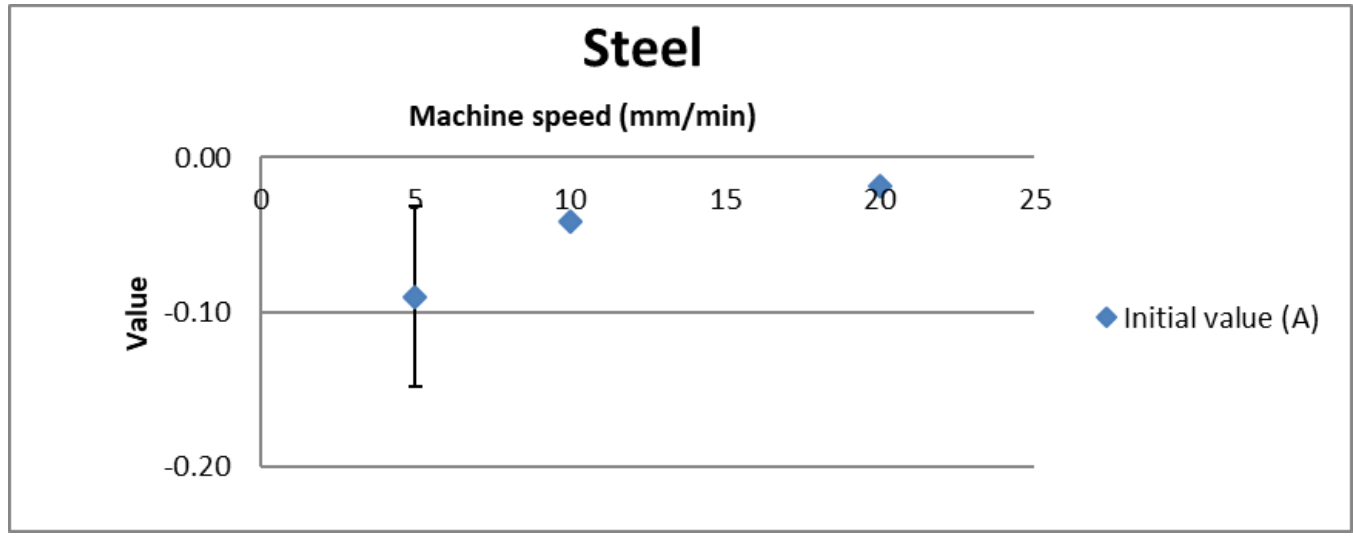

Figure 6. The initial value of the equation versus different loading rate for steel

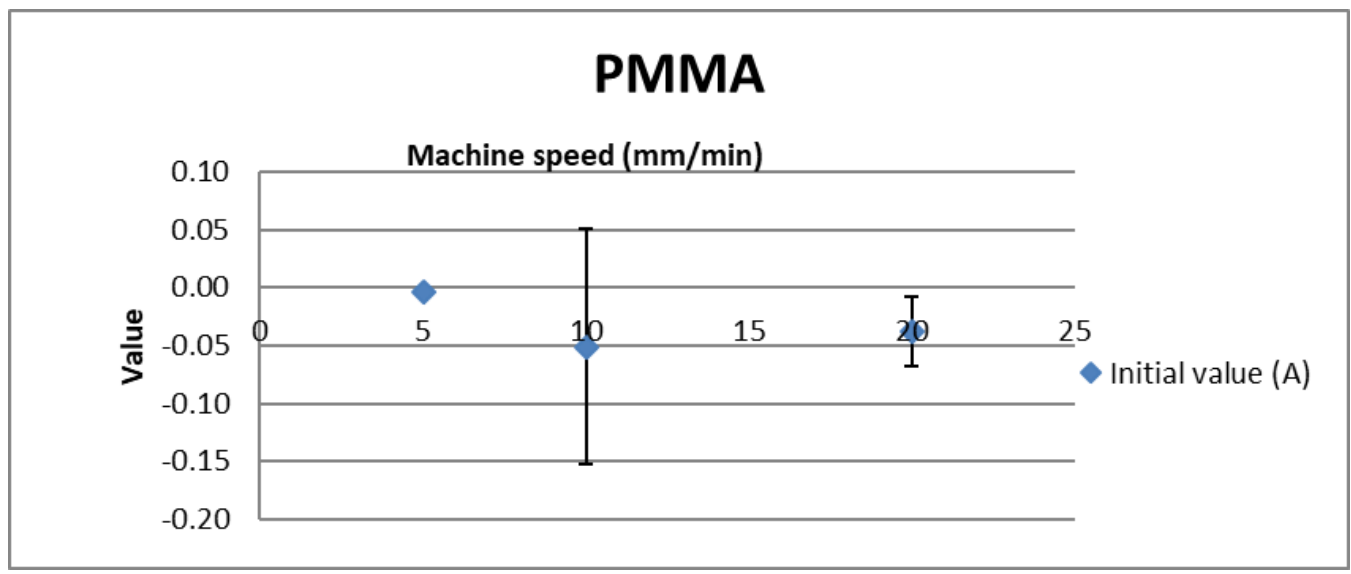

Figure 7. The initial value of the equation versus different loading rate for PMMA

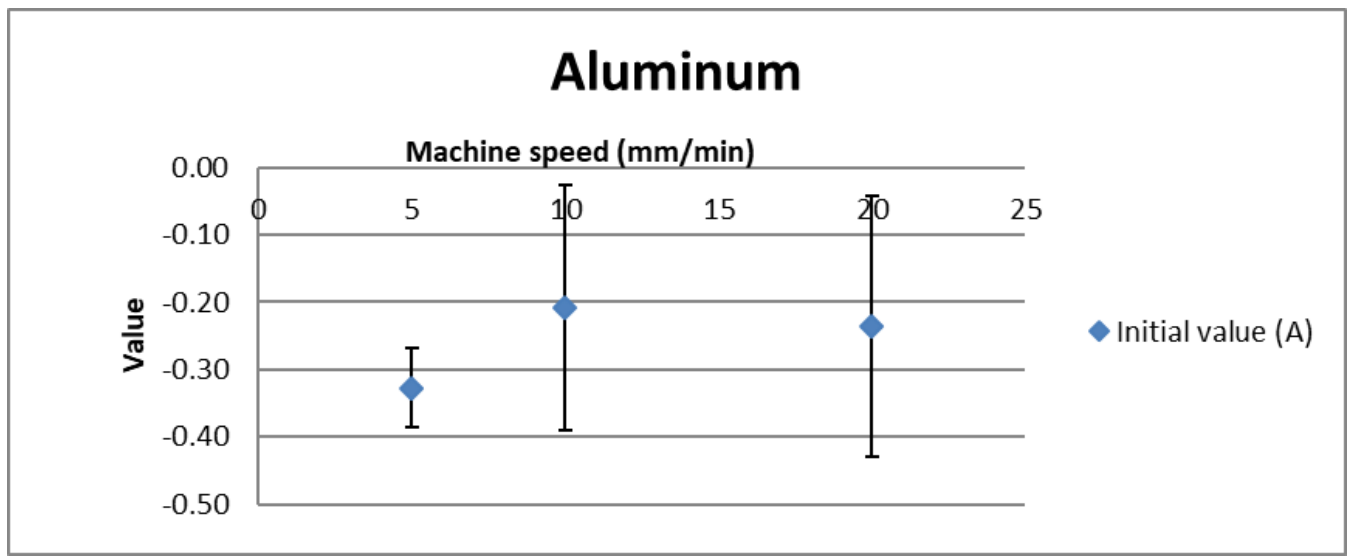

Figure 8 . The initial value of the equation versus different loading rate for Aluminium 


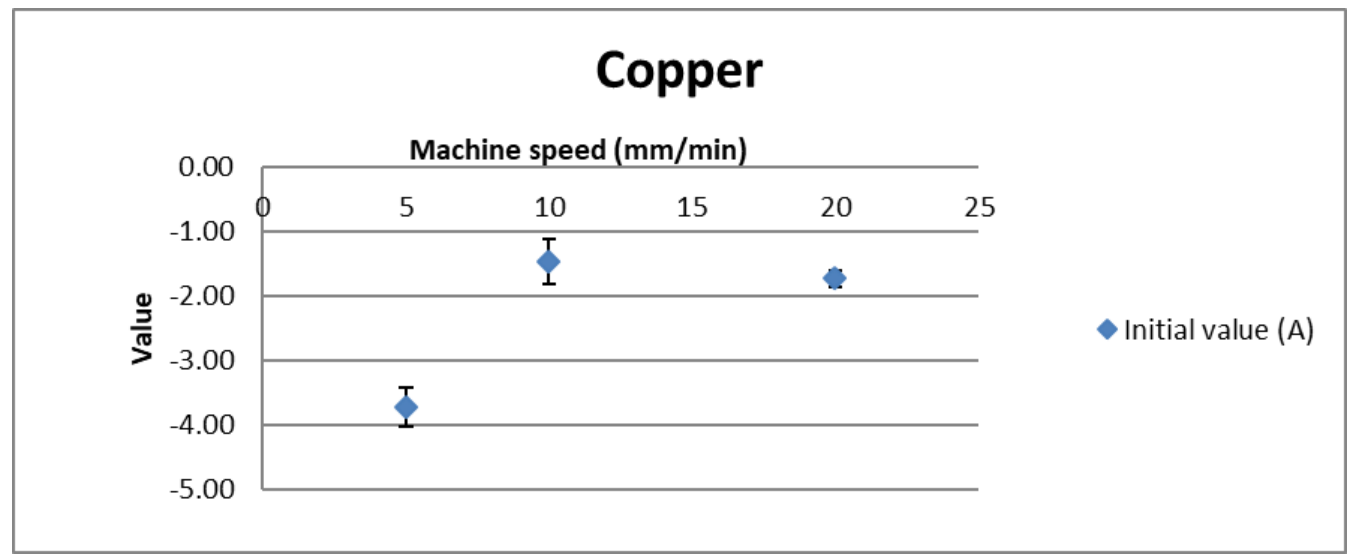

Figure 9. The initial value of the equation versus different loading rate for Copper

Figures 10 to 13 show the graphical representation of the increased at $10 \mathrm{~mm} / \mathrm{min}$ and then decreased at $20 \mathrm{~mm} / \mathrm{min}$. results of the coefficient $R_{0}$. Two of the ductile materials, Only the steel starts at a certain value at $5 \mathrm{~mm} / \mathrm{min}$ and still aluminium, and copper, with the brittle material, PMMA, stable at $10 \mathrm{~mm} / \mathrm{min}$ then increased at $20 \mathrm{~mm} / \mathrm{min}$. have a certain value of $R_{0}$ at machine speed $5 \mathrm{~mm} / \mathrm{min}$ then

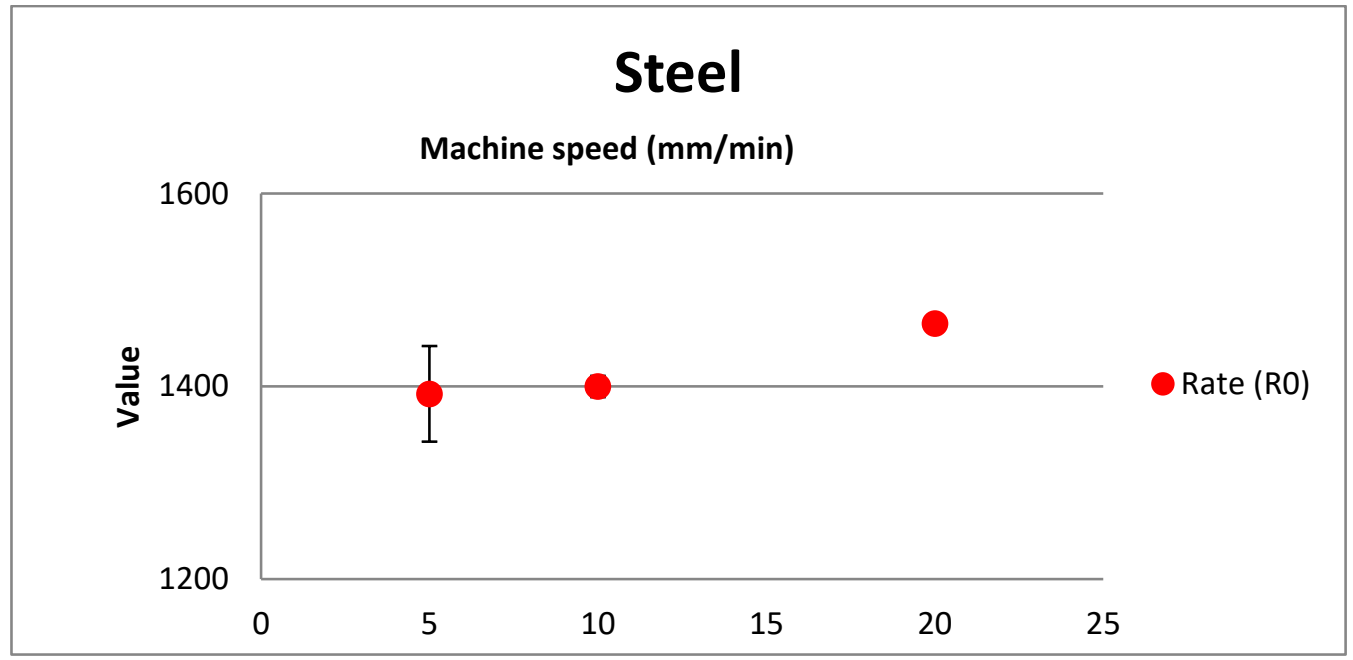

Figure 10. Loading rate value of the equation versus the fracture force for Steel

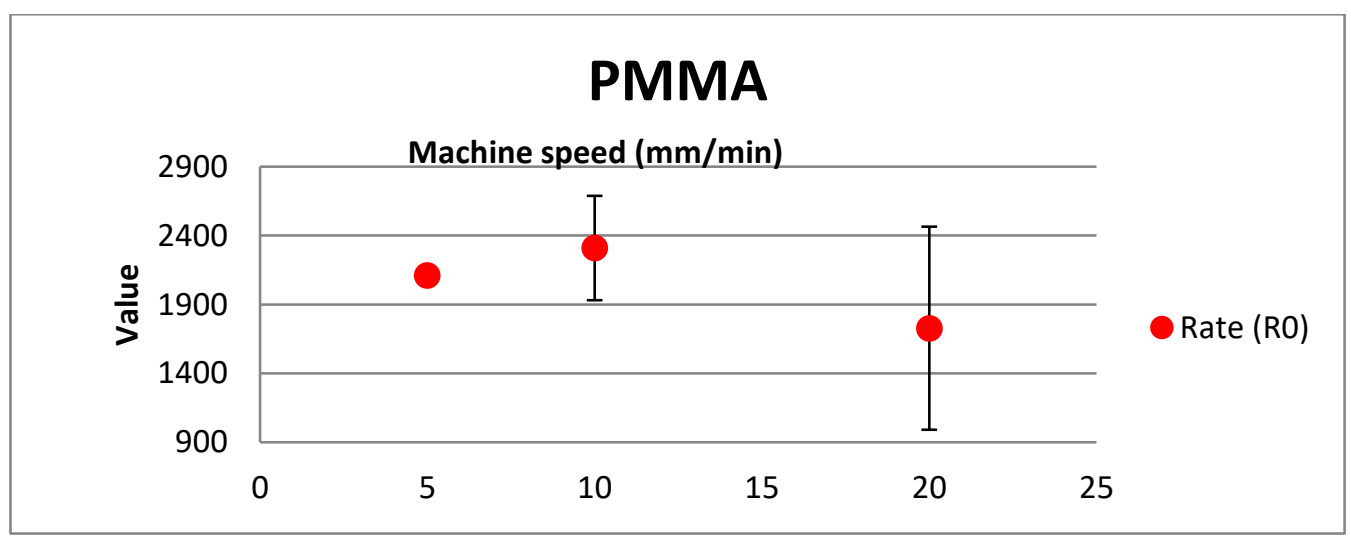

Figure 11. Loading rate value of the equation versus the fracture force for PMMA 


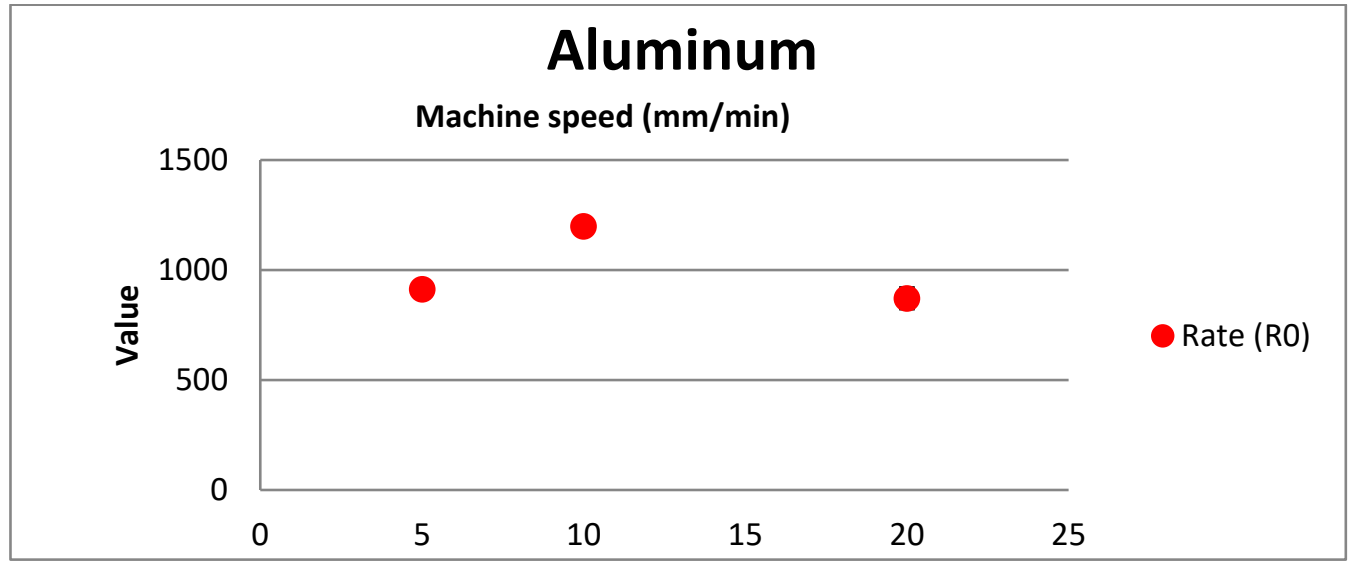

Figure 12. Loading rate value of the equation versus the fracture force for Aluminium

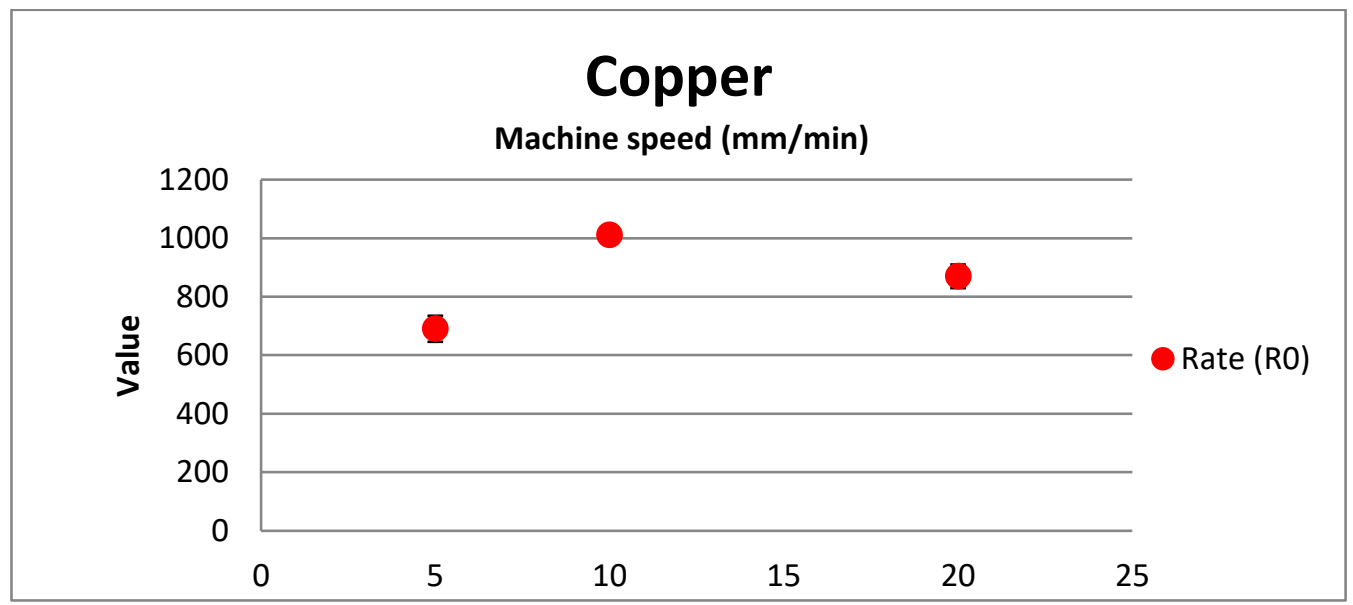

Figure 13. Loading rate value of the equation versus the fracture force for Copper

From the previous Figures ( 11 to 13 ), it was noted that test loading rate effect for ductile materials is behaving, in a similar manner, differing from that of quasi-brittle and the fracture mechanical behaviour of quasi-brittle materials is different from ductile materials, where cracks growth in ductile materials due to the intersections and coalescences of micro-void, while in quasi-brittle materials such as PMMA, crack propagation when the aggregates interlock or when micro-crack bridging occurs.

\section{CONCLUSION}

From this investigation, it was concluded that:

- Modelling of tension fracture and cracking in engineering and composite materials is an important issue to improve the load-bearing capacity and reliability of these materials. In this study, experimental work is used to model the fracture zone and to investigate the effects of loading rate. An empirical model was produced to correlate the fracture load with the loading rate and to predict and accurate determination of the fracture zone. This model improves the determination and analysis of fracture force prediction and is more accurate than other developed models.

- Test loading rate effect for ductile materials is behaving, in similar manner, differing from that of quasi-brittle and The fracture mechanical behaviour of ductile materials is different from that of quasi-brittle materials, where cracks growth in ductile materials due to the coalescences and intersections of micro-void, while in quasi-brittle materials such as PMMA, cracks propagate when the aggregates interlock or when micro-crack bridging occurs

- The difference of the material behaviour under dynamic and quasi-static loading is that the dynamic strength or yield stress increases as the strain rate increases. 


\section{REFERENCES}

G. Hutiu, V. Duma and A. Podoleanu, D. Demian, A. Bradu 2018, 'Assessment of Ductile, Brittle, and Fatigue Fractures of Metals Using Optical Coherence Tomography', Metals, vol. 8, p. 117 .

Z. Fan, J. Li, Y. Yang, J. Wang, Q. Li, S. Xue, H. Wang, J. Lou, X. Zhang 2017, "Ductile" Fracture of Metallic Glass Nanolaminates, Adv. Mater. Interfaces, vol. 4.

A. Pineau, A.A. Benzerga, T. Pardoen 2016, 'Failure of metals I: Brittle and ductile fracture', Acta Materialia, vol. 107.

M. Guptaab, R.C. Alder \& R. Benedictusb 2015, 'A review of T-stress and its effects in fracture mechanics', Engineering Fracture Mechanics, vol. 134, pp. 218-241.

Rui Tao Qu \& Zhe Feng Zhang 2013, A universal fracture criterion for high-strength materials', Scientific Reports, vol. 3,1117 .

A. Carpinteri, P. Cornetti, F. Barpi, S. Valente 2003, 'Cohesive crack model description of ductile to brittle size-scale transition: dimensional analysis vs. renormalization group theory', Engineering Fracture Mechanics, vol. 70, no. 14, pp. 1809-1839.

Andrew Braham 2016, State of the Art and Practice in Fatigue Cracking Evaluation of Asphalt Concrete, Ver1. Shane Underwood, Arizona State University.

R. Tao Qu \& Z. Feng Zhang 2013, 'A universal fracture criterion for high-strength materials', Scientific Reports, vol. 3,1117 .

L.H. Guo \& W.Q. Hu 2013, 'Fractal Research in Metal Material Fracture Invalidation', Advanced Materials Research, vol. 703, pp. 8-11.

N. Al-Maliky \& D.J Parry, 'Measurements of high strain rate properties of polymers using an expanding ring method', in 4th International Conference on Mechanical and Physical Behavior of Materials under Dynamic Loading, pp. 71-76.
Z.P. Bazant \& M.T. Kazem 1990, 'Determination of fracture energy, process zone length and brittleness number from size effect, with application to rock and concrete', International Journal of Fracture, vol. 44, pp. 111-131.

Z.P. Bazant 1985, 'Mechanics of Fracture and Progressive Cracking in Concrete Structures', eds G.C. Sih, A. Ditommaso and Martinus Nijhoff, in Fracture Mechanics of Concrete: Structureal Application and Numerical Calculation, pp. 1-94.

Z.P. Bazant, S. Lee \& P.A. Pfeiffer 1987, Engineering Fracture Mechanics 26, no. 1, pp. 45-57.

M. Alves 2000, 'Material constitutive law for large strains and strain rates', Journal of Engineering Mechanics, vol. 126, pp. $215-218$.

ISO 7500-1 2018, Metallic materials, Calibration and verification of static uniaxial testing machines, Part 1: Tension/compression testing machines, Calibration and verification of the force-measuring system. 